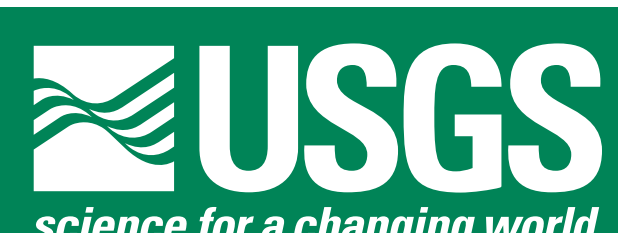

science for a changing world

\title{
How Brucite may Affect the Frictional Properties of Serpentinite
}

By Diane E. Moore', David A. Lockner ${ }^{1}$, K. Iwata ${ }^{2}$, H. Tanaka ${ }^{2}$, and J.D. Byerlee ${ }^{1}$

Open-File Report 01-320

2001

This report is preliminary and has not been reviewed for conformity with U.S. Geological Survey editorial standards or with the North American Stratigraphic Code. Any use of trade, firm, or product names is for descriptive purposes only and does not imply endorsement by the U.S. Government.

U.S. DEPARTMENT OF THE INTERIOR

U.S. GEOLOGICAL SURVEY

\footnotetext{
${ }^{1}$ Menlo Park, California

${ }^{2}$ Ehime University, Matsuyama, Japan
} 


\section{Abstract.}

The frictional strength of brucite gouge has been measured at hydrothermal conditions to $450^{\circ} \mathrm{C}$. At room temperature, brucite has a coefficient of friction, $\mu \approx 0.30$, making it one of the weakest minerals identified to date. With increasing temperature at a constant effective normal stress, the coefficient of friction of brucite decreases to a minimum of $\mu \approx 0.20$ near $300^{\circ} \mathrm{C}$, and $\mu \approx 0.22-0.24$ in the temperature range $350-450^{\circ} \mathrm{C}$. Brucite has a sheeted crystal structure, and its low frictional strength may be attributed to the relatively weak bonds between the layers. In addition, the temperature dependence of $\mu$ to $\approx 300^{\circ} \mathrm{C}$ can be explained in terms of the anomalously large coefficient of thermal expansion of brucite, which will further weaken the interlayer bonds. Brucite is a common constituent of serpentinite, and at $\approx 300^{\circ} \mathrm{C}$, where brucite is weakest, all the major serpentine minerals have $\mu \geq 0.5$. The maximum expected brucite content of a serpentinite is close to $20 \%$ by weight or volume. That amount of disseminated brucite will lower the coefficient of friction of serpentinite by $\leq 10-15 \%$ in the deeper parts of the seismogenic zone. However, the effect will be much greater if shear can be concentrated along brucite-lined slip surfaces in the serpentinite body.

\section{Introduction}

Brucite, $\mathrm{Mg}(\mathrm{OH})_{2}$, is one of the most important accessory minerals in serpentinite, where it principally forms as a by-product of the serpentinization of olivine [Hostetler et al., 1966]. Therefore, as part of our on-going investigations of the frictional properties of serpentinite, we have measured the strength of brucite gouge. Brucite is stable across essentially the entire pressure-temperature range of stability of the serpentine minerals [Evans et al., 1976], and we conducted experiments over the temperature range $25-450^{\circ} \mathrm{C}$ (Figure 1). Our results, reported in this paper, suggest that brucite is an unusually weak mineral throughout the seismogenic zone, and that under certain conditions it could significantly lower the shear strength of serpentinite-bearing fault zones.

\section{Experimental Methods}

The brucite starting material consists of clear, colorless, flexible lamellae from Lancaster County, Pennsylvania. Brucite from this locality is nearly pure $\mathrm{Mg}(\mathrm{OH})_{2}[\mathrm{Deer}$ et al., 1962b] that commonly is used in laboratory investigations [e.g., Brindley and Ogilvie, 1952; Neuvonen, 1952; Duffy and Ahrens, 1991]; the brucite in serpentinites characteristically contains about $15 \%$ of the Fe-end member $\mathrm{Fe}(\mathrm{OH})_{2}[$ Hostetler et al., 1966; Mumpton and Thompson, 1966]. Inclusions of a carbonate mineral and a dark green sheet silicate in the brucite sample were removed by hand, and the mineral separate was ground by hand sufficiently to pass through a $90-\mu \mathrm{m}$ sieve. An X-ray diffraction pattern of the prepared gouge contains only brucite peaks.

The experimental procedures are described in detail by Moore et al. [1997]. Briefly, the strength tests were run in a triaxial friction apparatus fitted with an internal furnace. For each experiment, a $1-\mathrm{mm}$ thick layer of gouge was placed along a $30^{\circ}$ sawcut in a $19.1-\mathrm{mm}$ diameter cylinder of antigoritic serpentinite. Serpentinite cylinders were used because the brucite gouge might have reacted with a quartz-rich rock type such as granite during the experiments at elevated temperatures. A borehole for pore-fluid entry was drilled into the upper half of the cylinder; the pore fluid was deionized water. The sample was housed in a copper jacket during each experiment to separate it from the confining-pressure medium. Reported strengths have been corrected for the strength of the jacket. The correction procedure for experiments to $290^{\circ} \mathrm{C}$, which involved shear of a teflon sheet inserted between steel forcing 


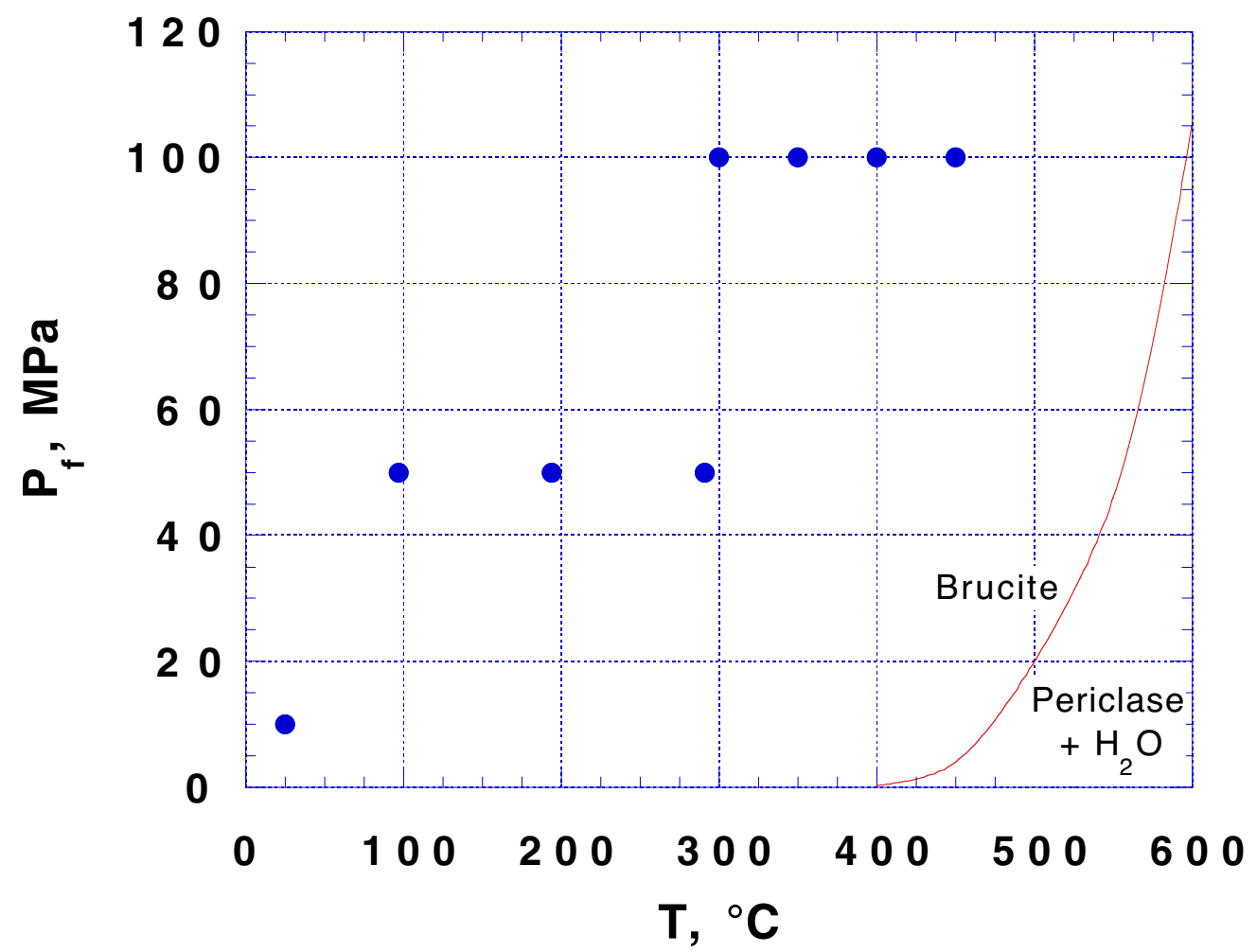

Figure 1. Temperature-fluid pressure conditions of the experiments of this study relative to the brucite-stability relations determined by Kennedy [1956], with data at $400^{\circ} \mathrm{C}$ from Webster and Roy [1965]. 
blocks, is presented by Moore et al. [1996a]. An additional correction at $400^{\circ} \mathrm{C}$ was determined during this study. For this determination, the effect of changing the width of the copper jacket was measured during shear of a layer of talc gouge placed in the steel forcing blocks.

Confining pressure was applied first to the sample, followed by the fluid pressure. After the pressures had equilibrated, the temperature was raised to the desired value. The experiments were all run at a constant normal stress, which was maintained by means of computer-controlled adjustments to the confining pressure. Temperature was monitored by a thermocouple inserted along the pore-pressure inlet. Partway through this series of experiments, we identified a problem with the temperature measurements, such that the actual temperatures of the affected samples were about 3\% lower than we thought (see Moore et al. [1997] for details). Corrected temperatures are used throughout this paper.

\section{Results}

The room-temperature brucite experiment (Figure 2) was run at $10 \mathrm{MPa}$ fluid pressure (1 $\mathrm{MPa}=10$ bars) and $110 \mathrm{MPa}$ normal stress, to maintain an effective normal stress of $100 \mathrm{MPa}$. Axial displacement rates were changed at intervals in the range 1-10 $\mu \mathrm{ms}^{-1}$. These velocity values represent the rate of advance of the piston; the nominal slip rate along the inclined sawcut would be $15.5 \%$ higher than the axial velocity. The conditions duplicate those of our earlier room-temperature experiments on the serpentine minerals [Moore et al., 1997], and those data are also included in Figure 2. At room temperature, the coefficient of friction, $\mu$, of brucite gouge is close to 0.30 , making brucite one of the weakest geologic materials identified to date. Weaker minerals include talc [e.g., HIckman et al., 1997] and the swelling clays montmorillonite and vermiculite [e.g., Summers and Byerlee, 1977a, b]. The serpentine mineral chrysotile also has a lower coefficient of friction than brucite (Figure 2), whereas $\mu$ is $50 \%$ higher for both lizardite and an antigorite-rich gouge than for brucite. The effect of velocity change on $\mu$ was measured for the room-temperature brucite sample (Table 1); calculation procedures and corrections are the same as those outlined by Moore et al.

Table 1. Velocity Data

\begin{tabular}{ccc}
\hline $\begin{array}{c}\text { Temperature } \\
\left({ }^{\circ} \mathrm{C}\right)\end{array}$ & $\begin{array}{c}\text { Velocity Step } \\
\left(\mu \mathrm{ms}^{-1}\right)\end{array}$ & $\Delta \mu / \Delta \ln \mathrm{V}$ \\
\hline \multirow{2}{*}{25} & $\begin{array}{c}1 \text { to } 3.2 \\
3.2 \text { to } 10\end{array}$ & +0.0048 \\
10 to 3.2 & +0.0043 \\
& 3.2 to 1 & +0.0047 \\
& 1 to 3.2 & +0.0054 \\
97 & 3.2 to 10 & +0.0007 \\
& 1 to 3.2 & -0.0007 \\
& 3.2 to 10 & 0 \\
& 1 to 3.2 & +0.0035 \\
391 & 1 to 3.2 & +0.0012 \\
300 & 1 to 3.2 & -0.0003 \\
\hline
\end{tabular}




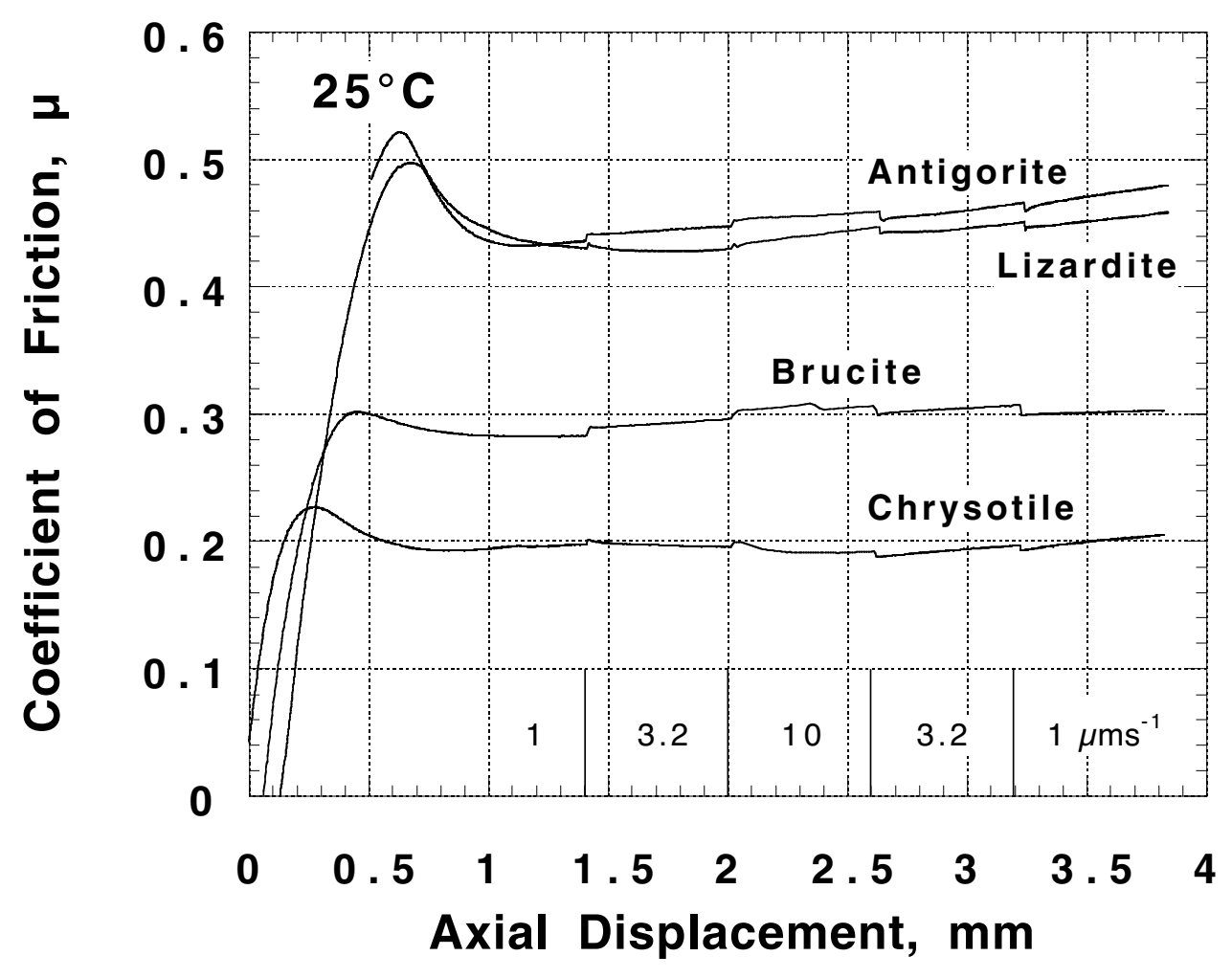

Figure 2. Comparative room-temperature frictional strengths of brucite and the three major serpentine minerals. All four experiments were conducted at $10 \mathrm{MPa}$ fluid pressure and $110 \mathrm{MPa}$ constant normal stress. The velocity at a given displacement interval is indicated at the bottom of the figure. 
[1996a]. The sliding rate sensitivity of shear strength is described by the change in coefficient of friction resulting from an exponential change in velocity, $\Delta \mu / \Delta \mathrm{lnV}$. Over this narrow velocity range, the data indicate an increase in $\mu$ with increasing velocity, that is, velocity strengthening behavior. The antigorite-rich gouge also tends to be velocity strengthening in this range, whereas chrysotile and lizardite more commonly are velocity weakening [Moore et al., 1997].

Fluid pressure was raised to $50 \mathrm{MPa}$ for the experiments conducted at temperatures of $97-291^{\circ} \mathrm{C}$ and to $100 \mathrm{MPa}$ for those at $300-450^{\circ} \mathrm{C}$ (Figure 1). Brucite, rather than its dehydration product periclase, $\mathrm{MgO}$, is stable at these fluid-pressure-temperature conditions [e.g., Kennedy, 1956; Weber and Roy, 1965]. The effective normal stress of all the heated experiments was $150 \mathrm{MPa}$, making the normal stress $200 \mathrm{MPa}$ at $97-291^{\circ} \mathrm{C}$ (Figure 3a) and $250 \mathrm{MPa}$ at $300-450^{\circ} \mathrm{C}$ (Figure $3 \mathrm{~b}$ ). An attempt was made to measure the velocity dependence of $\mu$, but this was largely unsuccessful because the heated jackets failed after relatively small amounts of displacement. The last few experiments, at $400-450^{\circ} \mathrm{C}$, were run at a single axial displacement rate of $1 \mu \mathrm{ms}^{-1}$. With heating, $\mu$ decreases gradually, and the samples slide stably at all temperatures (Figure 3). The coefficient of friction appears to reach a minimum of $\approx 0.20$ near $300^{\circ} \mathrm{C}$ and then to stabilize at $\approx 0.22-0.24$ between $340^{\circ}$ and $450^{\circ} \mathrm{C}$ (Figure 4). The changes in $\mu$ with increasing velocity determined for the heated samples tend to be positive, but the values are closer to zero than those for the room temperature samples (Table 1).

After the experiments, four of the heated samples (at $194^{\circ}, 300^{\circ}, 350^{\circ}$, and $450^{\circ} \mathrm{C}$ ) were recovered for bulk X-ray diffraction analysis. The single difference from the X-ray pattern of the starting material was the appearance of a low-intensity peak $\left(I / I_{100} \leq 2\right)$ at $\approx 2.1 \AA$ in the $450^{\circ} \mathrm{C}$ sample. This peak may correspond to the most intense peak of periclase, at $2.106 \AA$; as discussed below, the periclase probably is a quench product. A few fragments of gouge from these four samples were saved for observation with a scanning electron microscope. The brucite textures resemble those of the serpentinite gouges examined by Moore et al. [1997, Figures $8 \mathrm{~d}$ and $8 \mathrm{e}]$. Overall, the gouge consists of a stack of platy grains that are aligned roughly parallel to the sawcut. Shearing was concentrated along a few slickenlined surfaces, including ones situated near the gouge-sawcut boundary and ones that cross-cut the gouge layer ( $R$ shears). A cluster of euhedral crystals found on one slickenlined surface of the $450^{\circ} \mathrm{C}$ sample clearly formed after the cessation of shear. The crystals include some whose cubic shape suggests that they may be periclase rather than brucite. The $2.1 \AA$ peak in the $450^{\circ} \mathrm{C} X$-ray pattern may therefore represent periclase crystals that grew immediately upon jacket failure, when the pore fluid escaped and the stress on the shear surfaces was removed. The rapid kinetics of the reaction brucite $=$ periclase + water commonly leads to crystal growth during quenching of hydrothermal experiments [Barnes and Ernst, 1963; Schramke et al., 1982]. As illustrated in Figure 1 , the $450^{\circ} \mathrm{C}$ experiment is the only one in which a rapid loss of fluid pressure followed by slower cooling could lead to the crystallization of periclase.

\section{Discussion}

\subsection{Controls on Brucite Strength}

The minerals with unusually low frictional strength typically have a layered crystal structure, including the sheet-silicate minerals chrysotile, talc, montmorillonite, and vermiculite, mentioned previously, and the non-silicate mineral graphite [Summers and Byerlee, 1977b]. Brucite also has a sheeted structure, each layer consisting of a plane of $\mathrm{Mg}$ ions sandwiched between planes of $\mathrm{OH}$ ions [Deer et al., 1962b]. The low frictional strength of a given platy mineral may be caused by one or more of the following factors: the presence of 1) interlayer water or 2) adsorbed water, or 3) the weakness of interlayer bonds. The weakness of swelling clays such as montmorillonite or vermiculite has been attributed to the 


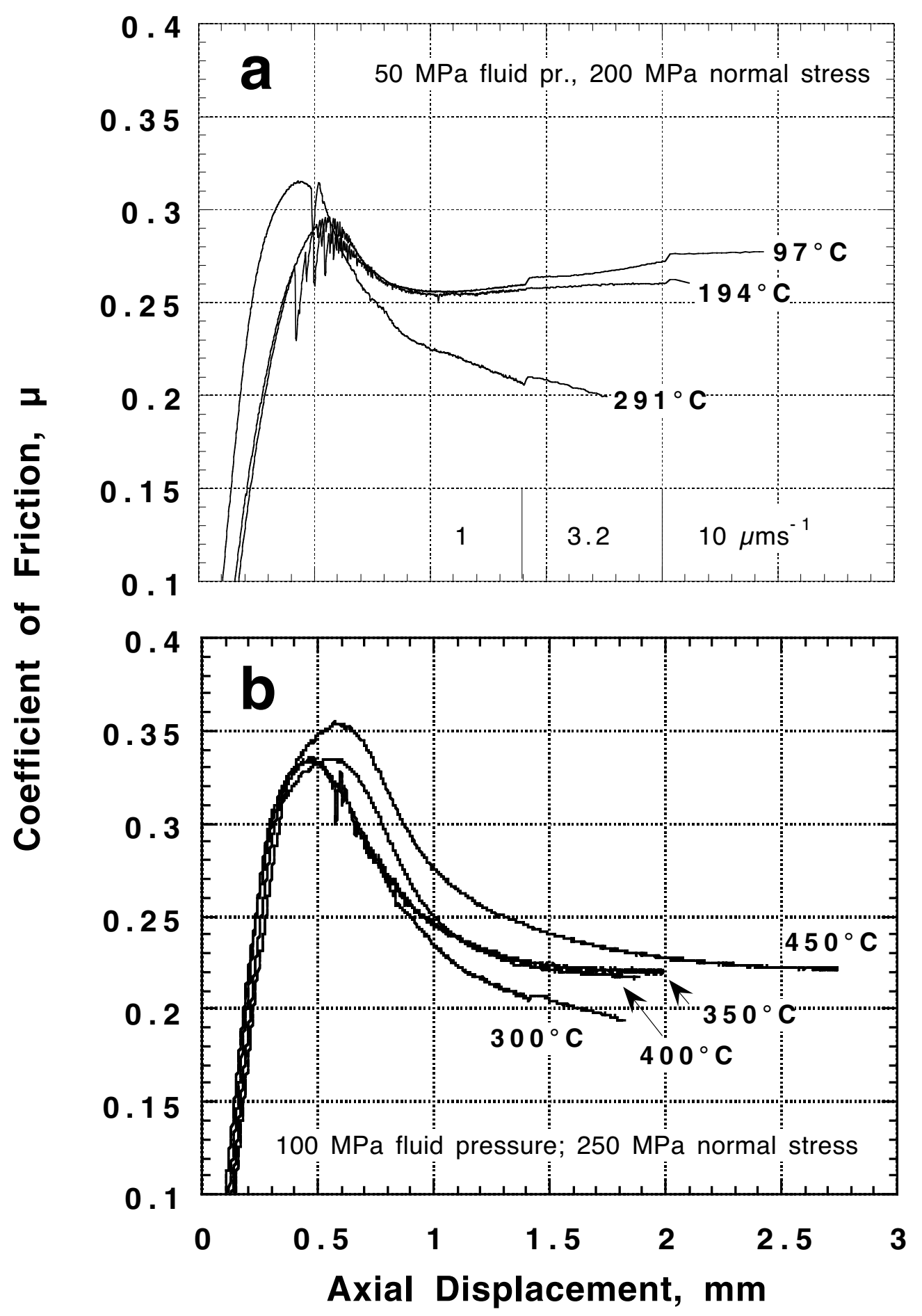

Figure 3. Coefficient of friction of brucite gouge relative to displacement at $150 \mathrm{MPa}$ effective normal stress at a) $97-291^{\circ} \mathrm{C}$ and $50 \mathrm{MPa}$ fluid pressure, and b) $300-450^{\circ} \mathrm{C}$ and $100 \mathrm{MPa}$ fluid pressure. Velocity stepping was attempted in the experiments at temperatures $\leq 340^{\circ} \mathrm{C}$; those experiments at $350-450^{\circ} \mathrm{C}$ were run at a constant axial velocity of $1 \mu \mathrm{m} / \mathrm{s}$. The $300^{\circ} \mathrm{C}$ experiment in b) follows the velocity sequence indicated in a). 


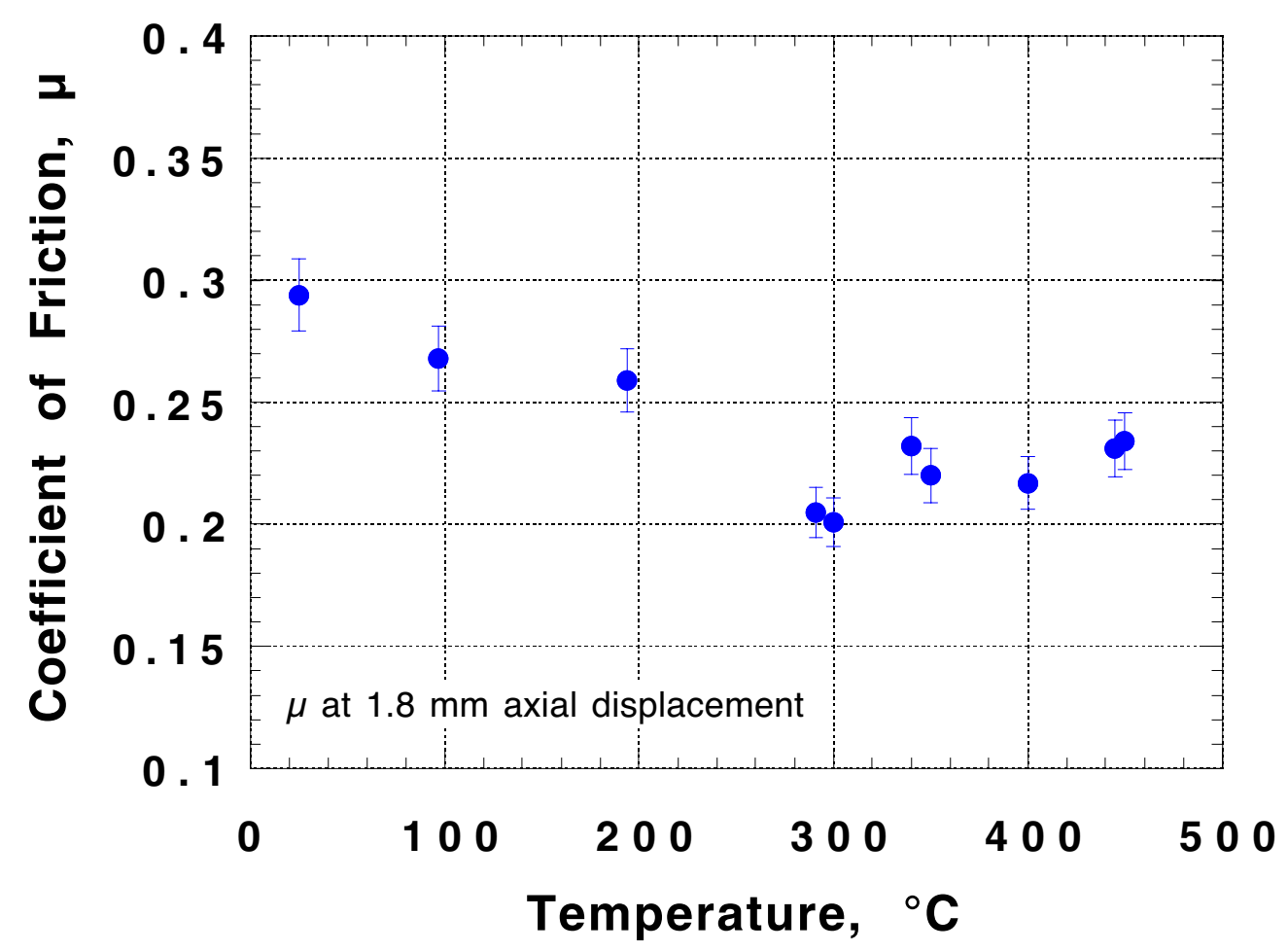

Figure 4. Coefficient of friction of brucite gouge at $1.8 \mathrm{~mm}$ axial displacement (the maximum displacement reached in all experiments), as a function of temperature. The room-temperature experiment was conducted at an effective normal stress of $100 \mathrm{MPa}$ and the heated experiments at $150 \mathrm{MPa}$. The error bars represent $\pm 5 \%$ of the value of $\mu$. 
incorporation of layers of water into the crystal lattice [Summers and Byerlee, 1977a]. Calcium montmorillonites commonly take on two water layers per unit cell and sodium montmorillonites occasionally more than three layers; the number of layers may vary across the thickness of a crystal [Deer et al., 1962a]. The shear strength of thin liquid films has been shown by Israelachvili et al. [1988] to be inversely proportional to the number of layers of liquid that comprise the film. The interlayer water of swelling clays is postulated to behave as a thin film of water, and shear may be concentrated within those crystals containing the largest number of water layers.

The serpentine mineral chrysotile adsorbs unusually large amounts of water; for example, Deer et al. [1962a] reported the adsorption of $2.5 \mathrm{wt} \% \mathrm{H}_{2} \mathrm{O}$ by a chrysotile sample, which increased its volume by more than 6\%. Moore et al. [1997] demonstrated experimentally that the very low frictional strength of chrysotile at room temperature (Figure 2 ) is caused by its adsorbed-water content, and that the coefficient of friction of dry chrysotile is at least a factor of 3 greater than that of wet chrysotile. Adsorbed water may affect frictional strength in a manner similar to that of interlayer water, in that thin liquid films covering the surfaces of crystals in a gouge would lower the stress required to slide one grain past another during shear. Many of the sheet silicate minerals adsorb at least small amounts of water, which will contribute to their somewhat reduced strength compared to quartz or feldspar [e.g., Summers and Byerlee, 1977a, b]. For both of these cases involving loosely bound water, an increase in temperature or confining pressure will drive off some proportion of that water from the crystals, thereby causing the coefficient of friction to increase [e.g., Bird, 1984; Moore et al., 1997].

The strength of the bonds that hold the layers together has also been hypothesized to control the shear strength of some platy minerals [e.g., Hickman et al., 1997]. Interlayer bond strengths vary widely among these minerals, ranging from the relatively strong ionic bonds characteristic of the brittle micas [Giese, 1978] to the very weak van der Waals forces between layers of talc [Deer et al., 1962a] and graphite [Mason and Berry, 1968]. Because of this, crystals of talc or graphite that are larger than one layer in thickness may be subject to shear localized in the plane of the van der Waals bonds. For this third mechanism to be the major control on frictional strength, the planes of weakness must be oriented favorably for shear, but such is commonly the case for both naturally deformed and laboratory-deformed materials rich in platy minerals.

Brucite does not adsorb water onto its crystal surfaces to any significant degree [Deer et al., 1962b], nor does it take on interlayer water. Instead, the low frictional strength of brucite is consistent with control principally by weak interlayer bonds. Brucite has a somewhat higher room-temperature coefficient of friction than talc and its interlayer bonds are also somewhat stronger than van der Waals forces [Deer et al., 1962b], the sheets of brucite being held together by dipole-dipole forces between opposing $\mathrm{OH}$ ions [e.g., Zigan and Rothbauer, 1967]. This bond strength nevertheless is lower than the hydrogen bonding of a sheet silicate such as kaolinite or serpentine [Giese, 1978, 1980], and brucite has a correspondingly lower coefficient of friction. The decrease in $\mu$ of brucite with heating to $\approx 300^{\circ} \mathrm{C}$ can also be explained in terms of interlayer bond strength. Redfern and Wood [1992] and Fei and Mao [1993] measured the thermal expansion of brucite at ambient pressure to temperatures of $310^{\circ}$ and $377^{\circ} \mathrm{C}$, respectively. They observed an unusually large, anisotropic thermal expansion, such that the linear expansion rate of the [c] lattice parameter, which measures the layer thickness, is approximately 5 times that of [a]. Both groups attributed the marked increase of $[c]$ to expansion of the dipole-dipole bond; this increase in bond length, in turn, should correspond to a decrease in its strength. Based on the cell dimension measurements made by Xia et al. [1998], [c] should continue to increase with increasing temperature to at least $600^{\circ} \mathrm{C}$, whereas our limited strength data for brucite suggest that $\mu$ is slightly higher at $350-450^{\circ} \mathrm{C}$ than at $300^{\circ} \mathrm{C}$ (Figure 4). Brucite also is characterized by a very large and equally anisotropic compressibility [e.g., Xia et al., 1998]. However, compression of the brucite lattice cannot explain our highest-temperature results because the heated experiments 
were all run at a constant effective normal stress and very similar effective pressures. This question needs to be addressed in future studies. The potentially competing effects of pressure and temperature on brucite strength should also be investigated in more detail, although the data of Xie et al. [1998] suggest that temperature effects should predominate over pressure effects in the seismogenic zone.

\subsection{Implications for the Frictional Strength of Serpentinites}

Figure 5, modified from Moore et al. [1996b], compares the shear strengths of brucite and the serpentine minerals relative to depth in the San Andreas fault zone, assuming a hydrostatic fluid-pressure gradient. The diagonally ruled area on the left delimits the restrictions on San Andreas fault strength in the seismogenic zone that would be required to explain the heat flow data of Brune et al. [1969] and Lachenbruch and Sass [1980].

Serpentinites had been suggested as a fault zone material that might be sufficiently weak at depth to satisfy the heat flow constraint on fault strength. However, the lizardite and antigorite varieties of serpentine are relatively strong at room temperature (Figure 2), and $\mu$ increases with increasing temperature for both gouges [Moore et al., 1997]. Correspondingly, their strengths at depth are relatively high, plotting not too far from the reference curve for granite in Figure 5. Chrysotile is weaker than brucite at low temperatures, and its shear-strength curve lies within the heat-flow field to about 3.5 kilometers depth. However, near its upper thermal limit of stability chrysotile is as strong as the other serpentine minerals. Thus, at depths of about $10 \pm 2 \mathrm{~km}$ where the larger earthquakes $\left(\mathrm{M}_{\mathrm{L}}>5.5\right)$ in California commonly are generated [Sibson, 1982], none of the serpentine minerals can produce a weak San Andreas fault under hydrostatic fluid pressure conditions (Figure 5). To shift all the chrysotile data in Figure 5 into the heat-flow field, the fluid pressure would have to be raised to $\geq 65 \%$ of the lithostatic pressure at $6 \mathrm{~km}$ depth and to $\geq 78 \%$ at $9 \mathrm{~km}$ [Moore et al., 1996b].

In contrast to the serpentine minerals, the coefficient of friction of brucite is low throughout the entire temperature range of the seismogenic zone, and its shear strength is close to the upper limit of strength imposed by the heat flow data. To shift the brucite data point at $\approx 9 \mathrm{~km}$-depth to that upper limit requires fluid pressures only slightly above hydrostatic levels, at $\approx 45 \%$ of the overburden pressure.

The serpentinization of olivine provides the principal source of brucite in an ultramafic rock, generated according to the following reactions:

$$
\begin{aligned}
& 2 \mathrm{Mg}_{2} \mathrm{SiO}_{4}+3 \mathrm{H}_{2} \mathrm{O}=\mathrm{Mg}_{3} \mathrm{Si}_{2} \mathrm{O}_{5}(\mathrm{OH})_{4}+\mathrm{Mg}(\mathrm{OH})_{2} \\
& \text { Mg-olivine chrysotile/lizardite brucite }
\end{aligned}
$$

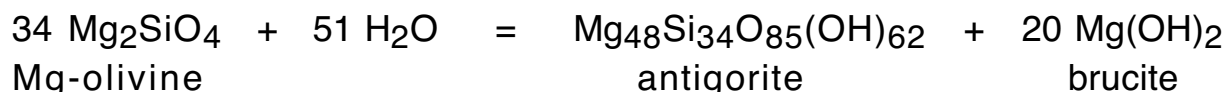

Reaction (1) is appropriate for the low-temperature serpentine minerals chrysotile and lizardite, whose compositions can approach the ideal formula. This reaction would generate a serpentinite containing slightly less than $20 \%$ brucite by either weight or volume, calculated using density data from Deer et al. [1962a, b]. The structural modifications of antigorite relative to the basic platy configuration of serpentine lowers its $\mathrm{MgO}$ and $\mathrm{H}_{2} \mathrm{O}$ contents relative to other serpentine minerals. As a result, reaction (2) [Evans et al., 1976] generates slightly more than $20 \%$ brucite by weight or volume. The maximum possible brucite content of a serpentinite is thus expected to be $\approx 20 \%$, and natural serpentinites typically contain $<20-25 \%$ brucite [Hostetler et al., 1966; Mumpton and Thompson, 1975]. Several factors can combine to lower the brucite content from this maximum. Because of the lower Mg/Si ratio of enstatite $\left(\mathrm{MgSiO}_{3}\right)$ compared to olivine, a serpentinized orthopyroxene-bearing ultramafic rock will have a larger serpentine-mineral content and a lower brucite content than a pure-olivine dunite. Additionally, if the fluids involved in serpentinization are rich in dissolved silica, more 


\section{Shear Strength, MPa}

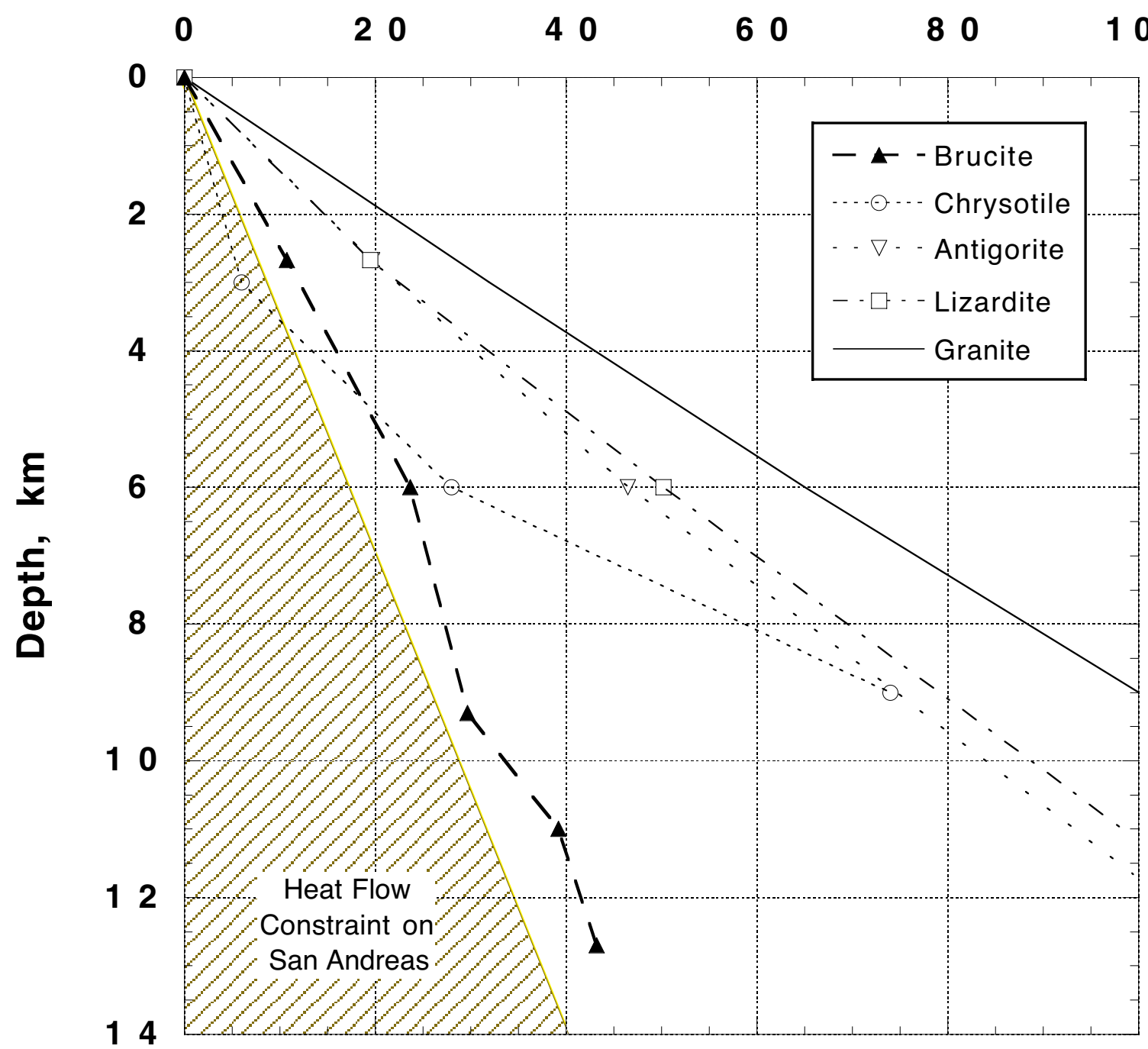

Figure 5. Shear strengths of brucite and the major serpentine minerals, in the presence of a hydrostatic fluid-pressure gradient and a geothermal gradient of $30^{\circ} \mathrm{C} / \mathrm{km}$; serpentine-mineral data are from Moore et al. [1997]. The diagonally ruled field represents the range of shear strengths that are consistent with the heat-flow data of Brune et al. [1969] and Lachenbruch and Sass [1980]; their upper limit of $20 \mathrm{MPa}$ average shear strength is plotted for a 14-km deep seismogenic zone, assuming that $\mu$ remains constant at depth. A strength profile for granite [Blanpied at al., 1995] is included as a reference curve. Modified from Fig. 3 of Moore et al. [1996b]. 
serpentine can crystallize at the expense of brucite. In the same way, $\mathrm{CO}_{2}$-bearing fluids, which may be common in the San Andreas and other faults [Irwin and Barnes, 1980; Kennedy et al., 1997], might promote the crystallization of magnesite $\left(\mathrm{MgCO}_{3}\right)$ instead of brucite at deep levels. Some excess $\mathrm{Mg}$ may also be removed in solution, as part of migrating fluids.

If approximately $20 \%$ brucite is disseminated throughout a serpentinite gouge, it will lower the coefficient of friction by about 10-15\%, assuming that the coefficient of friction of a gouge varies linearly with its mineral content. A component comprising $\leq 25 \%$ of a gouge may actually have slightly less effect on $\mu$ than predicted from its abundance [Logan and Rauenzahn, 1987]. Such a small change in $\mu$ will not shift any of the serpentine-mineral curves in Figure 5 to significantly lower shear strengths, and a serpentinite with a smaller brucite content will be even less affected. However, shear strengths approaching the brucite curve could be approached if the brucite were concentrated in veins that then became the locus of shear. Although the brucite that initially crystallizes in a serpentinite generally is fine-grained and intimately mixed with serpentine minerals, textural evidence exists that some of this brucite may later be concentrated in veins, at least at a small scale [Hostetler et al., 1966; Mumpton and Thompson, 1966, 1975]. Based on the limited velocity data acquired in this study, a brucite-lined slip surface not only would be weak but also a possibly stabilizing influence on fault slip, because a velocity-strengthening material will tend to slip stably. Our results for brucite might therefore have application to the creeping portions of the San Andreas system. A possible problem with this hypothesis is that if shearing is accompanied by fluid flow, the brucite potentially could react with those fluids to form minerals such as magnesite or serpentine, as described above (see also Page [1968]). Nevertheless, it would be worthwhile to examine natural serpentinite-filled faults for evidence of shear localization associated with brucite, as a test of the hypothesis.

\section{Conclusions}

Brucite is yet another mineral with a sheeted crystal structure that has a low frictional strength. The weak dipole-dipole bonds that hold the layers of brucite together may be the principal cause of its low room-temperature coefficient of friction and the decrease in $\mu$ with temperature increase to $\approx 300^{\circ} \mathrm{C}$. Brucite is sufficiently weak that fluid pressures only slightly above hydrostatic levels would be required for a brucite-filled fault to satisfy the heatflow constraints on San Andreas fault strength. The principal occurrence of brucite in fault zones is as a constituent of serpentinites, and all the major serpentine minerals will be relatively strong in the deeper parts of the seismogenic zone. The brucite content of a serpentinite is limited to $\leq 20-25 \%$ by weight or volume; thus, the brucite would have to be concentrated along the principal slip surfaces rather than mixed in with the serpentine minerals in order to substantially lower the strength of a serpentinite-filled fault. Because brucite may react with silica- or $\mathrm{CO}_{2}$-rich fluids to produce other, potentially stronger minerals, the chemistry and volume of any fluids involved with shearing will determine whether or not the weakness of brucite-lined slip surfaces is a viable explanation of low shear stresses along some faults.

\section{References}

Barnes, H. L., and Ernst, W. G., Ideality and ionization in hydrothermal fluids: The system MgO - $\mathrm{H}_{2} \mathrm{O}-\mathrm{NaOH}$, Am. J. Sci., 261, 129-150, 1963.

Bird, P., Hydration-phase diagrams and friction of montmorillonite under laboratory and geologic conditions, with implications for shale compaction, slope stability, and strength of fault gouge, Tectonophysics, 107, 235-260, 1984. 
Blanpied, M. L., Lockner, D. A., and Byerlee, J. D., Frictional slip of granite at hydrothermal conditions, J. Geophys. Res., 100, 13,045-13,064, 1995.

Brindley, G. W., and Ogilvie, G. J., The texture of single crystals of brucite, Acta Crystallogr., $5,412-413,1952$.

Brune, J. N., Henyey, T. L., and Roy, R. F., Heat flow, stress, and rate of slip along the San Andreas fault, California, J. Geophys. Res., 74, 3821-3827, 1969.

Deer, W. A., Howie, R. A., and Zussman, J., Rock-Forming MInerals, Vol. 3. Sheet Silicates, 270 pp., John Wiley and Sons, Inc., New York, 1962a.

Deer, W. A., Howie, R. A., and Zussman, J., Rock-Forming Mlnerals, Vol. 5. Non-Silicates, pp. 89-92, John Wiley and Sons, Inc., New York, 1962b.

Duffy, T. S., and Ahrens, T. J., The shock wave equation of state of brucite $\mathrm{Mg}(\mathrm{OH})_{2}, \mathrm{~J}$. Geophys. Res., 96, 14,319-14,330, 1991.

Evans, B. W., Johannes, W., Oterdoom, H., and Trommsdorff, V., Stability of chrysotile and antigorite in the serpentinite multisystem, Schweiz. Miner. Petrog. Mitt., 56, 79-93, 1976.

Fei, Y., and Mao, H.-K., Static compression of $\mathrm{Mg}(\mathrm{OH})_{2}$ to $78 \mathrm{GPa}$ at high temperature and constraints on the equation of state of fluid $\mathrm{H}_{2} \mathrm{O}$, J. Geophys. Res., 98, 11,875-11,884, 1993.

Giese, R. F., The electrostatic interlayer forces of layer structure minerals, Clays Clay Miner., 26, 51-57, 1978.

Giese, R. F., Jr., Hydroxyl orientations and interlayer bonding in amesite, Clays Clay Miner., 28, 81-86, 1980.

Hickman, J. B., Zhurina, E. N., and Kronenberg, A. K., Deformation of talc and pyrophyllite: Disruption of van der Waals bonds and comparisons with calculated interlayer forces (abstract), EOS Trans. AGU, 78(46), Fall Meet. Suppl., F724, 1997.

Hostetler, P. B., Coleman, R. G., Mumpton, F. A., and Evans, B. W., Brucite in alpine serpentinites, Am. Mineral., 51, 75-98, 1966.

Irwin, W. P., Barnes, I., Tectonic relations of carbon dioxide discharges and earthquakes, J. Geophys. Res., 85, 3115-3121, 1980.

Israelachvili, J. N., McGuiggan, P. M., and Homola, A. M., Dynamic properties of molecularly thin liquid films, Science, 240, 189-191, 1988.

Kennedy, B. M., Kharaka, Y. K., Evans, W. C., Ellwood, A., DePaolo, D. J., Thorsden, J., Ambats, G., and Mariner, R. H., Mantle fluids in the San Andreas fault system, California, Science, 278, 1278-1281, 1997.

Kennedy, G. C., The brucite-periclase equilibrium, Am. J. Sci., 254, 567-573, 1956.

Lachenbruch, A. H., and Sass, J. H., Heat flow and energetics of the San Andreas fault zone, J. Geophys. Res., 85, 6185-6222, 1980.

Logan, J. M., and Rauenzahn, K. A., Frictional dependence of gouge mixtures of quartz and montmorillonite on velocity, composition and fabric, Tectonophysics, 144, 87-108, 1987.

Mason, B., and Berry, L. G., Elements of Mineralogy, pp. 219-222, W. H. Freeman and Company, San Francisco, 1968.

Moore, D. E., Lockner, D. A., Summers, R., Byerlee, J. D., and Ma, S., Sample characterizations and strength measurements of serpentinite gouges, U. S. Geol. Surv. Open-File Rep., 96-702, 88 pp., 1996a.

Moore, D. E., Lockner, D. A., Summers, R., Ma, S., and Byerlee, J. D., Strength of chrysotileserpentinite gouge under hydrothermal conditions: Can it explain a weak San Andreas fault?, Geology, 24, 1041-1044, 1996b.

Moore, D. E., Lockner, D. A., Ma, S., Summers, R., and Byerlee, J. D., Strengths of serpentinite gouges at elevated temperatures, J. Geophys. Res., 102, 14,787-14,801, 1997.

Mumpton, F. A., and Thompson, C. S., The stability of brucite in the weathering zone of the New Idria serpentinite, Proc. 14th Nat. Conf. Clays Clay Miner., 249-257, 1966.

Mumpton, F. A., and Thompson, C. S., Mineralogy and origin of the Coalinga asbestos deposits, Clays Clay Miner., 23, 131-143, 1975. 
Neuvonen, K. J., Thermochemical investigations of the åkermanite-gehlenite series, Bull. Comm. Géol. Finlande, no. 158, 50 pp., 1952.

Page, N. J., Chemical differences among the serpentine "polymorphs", Am. Mineral., 53, 201-215, 1968.

Redfern, S. A. T., and Wood, B. J., Thermal expansion of brucite, $\mathrm{Mg}(\mathrm{OH})_{2}, A m$. Mineral., 77, 1129-1132, 1992.

Schramke, J. A., Kerrick, D. M., and Blencoe, J. G., Experimental determination of the brucite = periclase + water equilibrium with a new volumetric technique, Am. Mineral., 67, 269-276, 1982.

Sibson, R. H., Fault zone models, heat flow, and the depth distribution of earthquakes in the continental crust of the United States, Bull. Seismol. Soc. Am., 72, 151-163, 1982.

Summers, R. and Byerlee, J., A note on the effect of fault gouge composition on the stability of frictional sliding, Int. J. Rock Mech. Min. Sci., 14, 155-160, 1977a.

Summers, R. and Byerlee, J., Summary of results of frictional sliding studies, at confining pressures up to $6.98 \mathrm{~kb}$, in selected rock materials, U. S. Geol. Surv. Open-File Rep., 77142, 129 pp., 1977b.

Weber, J. N., and Roy, R., Complex stable = metastable solid reactions, illustrated with the $\mathrm{Mg}(\mathrm{OH})_{2}=\mathrm{MgO}$ reaction, Am. J. Sci., 263, 668-677, 1965.

Xia, X., Weidner, D. J., and Zhao, H., Equation of state of brucite: Single-crystal Brillouin spectroscopy study and polycrystalline pressure-volume-temperature measurement, $A m$. Mineral., 83, 68-74, 1998.

Zigan, F., and Rothbauer, R., Neutronenbeugungsmessungen am Brucit, Neues Jahrbuch für Mineralogie Monatshefte, 137-143, 1967. 